\title{
RECUPERAÇÃO DE UM SOLO DEGRADADO COM A APLICAÇÃO DE ADUBOS VERDES E LODO DE ESGOTO(1)
}

\author{
Aline Emy Kitamura ${ }^{(2)}$, Marlene Cristina Alves ${ }^{(3)}$, Luiz Gustavo \\ Akihiro Sanches Suzuki ${ }^{(4)}$ \& Antonio Paz Gonzalez ${ }^{(5)}$
}

\begin{abstract}
RESUMO
A utilização incorreta dos solos vem causando alterações neles, tornando-os cada vez menos produtivos, aumentando as áreas com solos degradados. $O$ presente trabalho teve por objetivos estudar ações para acelerar a formação do horizonte $A$ de um Latossolo Vermelho degradado, via uso de adubos verdes, lodo de esgoto e cultivo de uma espécie arbórea nativa de Cerrado, e selecionar indicadores para detectar alterações da camada superficial do solo. $O$ monitoramento das alterações do solo foi realizado anualmente. O delineamento experimental foi o de blocos casualizados com seis tratamentos, em cinco repetições. Os tratamentos foram: testemunha - solo exposto (sem manejo); vegetação nativa (Cerrado); espécie arbórea Astronium fraxinifolium; Astronium fraxinifolium + Canavalia ensiformis; Astronium fraxinifolium + Raphanus sativus; e Astronium fraxinifolium + Brachiaria decumbens + lodo de esgoto $\left(60 \mathrm{t} \mathrm{ha}^{-1}\right)$. Avaliou-se no solo: porosidade, densidade do solo, cátions trocáveis, $\mathrm{pH}$, acidez potencial $(\mathrm{H}+\mathrm{Al})$, soma de bases (SB), saturação por bases (V), CTC e macrorganismos. Nos adubos verdes, foi avaliada a massa seca e, para a espécie arbórea, a altura e o diâmetro de caule. A mobilização do solo e a mobilização mais a adubação verde e o lodo de esgoto estão recuperando as propriedades do solo degradado, com comportamento semelhante entre elas após um ano de adoção. $\mathbf{O}$ melhor indicador físico das alterações do solo foi sua densidade. Os tratamentos adotados são semelhantes quanto à população de macrorganismos do solo e contribuindo positivamente para recuperação da macrofauna. A presença de larva e besouro foi indicadora da melhoria da macrofauna do solo.
\end{abstract}

Termos de indexação: área de empréstimo, densidade do solo, porosidade do solo, fertilidade do solo, macrorganismos do solo.

\footnotetext{
(1) Parte do trabalho de doutorado desenvolvido no Programa de Pós-Graduação em Sistemas de Produção - UNESP/Campus de Ilha Solteira. Recebido para publicação em junho de 2006 e aprovado em setembro de 2007.

${ }^{(2)}$ Doutoranda do Programa de Pós-Graduação em Sistemas de Produção, Faculdade de Engenharia, Universidade Estadual Paulista - UNESP. Caixa Postal 31, CEP 15385-000 Ilha Solteira (SP). Bolsista CAPES. E-mail: alineemy@gmail.com

${ }^{(3)}$ Professora Livre Docente, Departamento de Fitossanidade, Engenharia Rural e Solos, UNESP. Bolsista do CNPq. E-mail: mcalves@agr.feis.unesp.br

(4) Graduando do Curso de Agronomia, UNESP. Bolsista de iniciação científica/CNPq. E-mail: lg_suzuki@yahoo.com.br

(5) Professor Catedrático, Facultad de Ciencias, Universidade da Coruña, Espanha. 15071 La Coruña, Espanha. E-mail: tucho@udc.es
} 


\title{
SUMMARY: RECOVERY OF A DEGRADED SOIL WITH GREEN MANURE AND SEWAGE SLUDGE
}

\begin{abstract}
The inadequate use of soils induces alterations, exhausting the productivity, and resulting in growing areas of degraded soil. This study had the objectives of a) studying alternatives to promote the formation of the A horizon of a degraded soil through the use of green manure, sewage sludge, and cultivation of a native tree species; and b) selecting soil quality indicators to detect the alterations in the surface layer. Evaluations were executed annually. The experimental design was in random blocks with six treatments and five replications. The treatments consisted of a control (without soil management); original vegetation (savannah); Astronium fraxinifolium; Astronium fraxinifolium + Canavalia ensiformis; Astronium fraxinifolium + Raphanus sativus and Astronium fraxinifolium + Brachiaria decumbens + sewage sludge $\left(60 t \mathrm{ha}^{-1}\right)$. The following soil properties were evaluated: porosity, bulk density, exchangeable cations, $\mathrm{pH}$, potential acidity, base saturation, CEC and macrofauna. The dry matter of the green manures was evaluated. and stem height and diameter of the tree species were measured. Soil mobilization or soil mobilization plus green manure or sewage sludge restored soil properties, although the effects are similar after one year. The best soil physical quality indicator was bulk density. The effects of treatments on the recovery of soil macrofauna were similar. The presence of larvae and beetles was an indication of the improvement in the soil macrofauna.
\end{abstract}

Index terms: loan area, bulk density, soil porosity, soil fertility, soil macrofauna.

\section{INTRODUÇÃ̃O}

Com o aumento da população mundial, a necessidade cada vez maior de alimentos, de espaço e de condições para sobrevivência faz com que as ações antrópicas ao ambiente sejam crescentes. A história do uso do solo mostra que a alteração no ambiente nem sempre dá lugar a um novo sistema ecológico sustentável, seja de lavouras ou de pastagens. Com isso, solos utilizados intensamente, e de forma inadequada, são levados à degradação (Alves, 2001).

Com o aumento no consumo de energia elétrica, torna-se necessária a construção de novas usinas hidrelétricas. Com isso, de um lado, resultam as chamadas "áreas de empréstimo", que são os locais de onde se retiram materiais para formação do corpo da barragem (Lopes \& Queiroz, 1994); e, de outro, a inundação de grandes áreas, com a formação dos lagos. Essa situação modifica as condições edafoclimáticas da área. Ainda que a hidroeletricidade, como alternativa para produção de energia, possa ser considerada ambientalmente mais vantajosa em relação a outras opções, por utilizar um recurso natural renovável e não-poluente, a formação de reservatórios implica ocorrência de diversos impactos ao ambiente, atingindo elementos físicos, biológicos e socioeconômicos (CESP, 1998). O uso de cobertura vegetal como medida mitigadora dos impactos ambientais é uma opção coerente, prática e econômica, embora apresente dificuldades de adaptação inerentes ao novo sistema ecológico que se desenvolve no local de origem (Neves et al., 2001).

Em um planejamento de recuperação de área degradada, o grande desafio a ser alcançado é o estabelecimento de um horizonte A, para que, a partir daí, o processo seja catalisado pela biosfera, podendo surgir outros horizontes, conforme o condicionamento natural. Desse modo, interfere-se em um ou mais fatores de formação do solo, numa tentativa de acelerar sua gênese. Portanto, em trabalho de recuperação, a primeira atividade compreende a identificação e caracterização dos processos de degradação atuantes e a análise de suas conseqüências ambientais. Para isso, é necessário o uso de indicadores que traduzam quantitativa ou qualitativamente o grau da degradação existente e, ainda, permitam estimar a dimensão dos esforços técnicos e econômicos que deverão ser alocados na recuperação (Bitar, 1997). Assim, na recuperação de áreas degradadas, a definição e o uso de indicadores de avaliação e monitoramento de ecossistemas naturais têm sido muito discutidos.

Stenberg (1999) enfatizou que nenhum indicador individualmente conseguirá descrever e quantificar todos os aspectos de qualidade do solo. Nem mesmo uma única qualidade do solo pode ser avaliada,já que deve haver relação entre todas as suas propriedades. Assim, um número mínimo de propriedades deve ser selecionado. Os critérios para seleção de indicadores relacionam-se, principalmente, com sua utilidade em definir os processos do ecossistema. Estes integram as propriedades físicas, químicas e biológicas, além da sensibilidade ao manejo e variações climáticas (Doran, 1997).

A adição de várias fontes de material orgânico tem sido utilizada com o objetivo de melhorar as propriedades do solo. Nascimento et al. (2003) mencionaram que em solo degradado as leguminosas contribuíram 
para a diminuição da acidez do solo, elevando o $\mathrm{pH}$ no perfil e os teores de Ke Mg. Já Alves \& Suzuki (2004) observaram que o uso de plantas de cobertura aliado à sucessão de culturas (milho e soja) sob semeadura direta melhorou as propriedades físicas do solo, como porosidade, densidade do solo e resistência mecânica à penetração. Aguiar et al. (2000) afirmaram que uma alternativa que pode acelerar a recuperação das áreas degradadas é a utilização de espécies nativas do local, junto com espécies que acelerem o equilíbrio químico e físico do solo, sendo de grande relevância para o reequilíbrio do ecossistema os adubos verdes, que são importantes na cobertura inicial do solo.

O problema de degradação da área em estudo foi gerado em conseqüência da construção da Usina Hidrelétrica de Ilha Solteira-SP. Mediante o exposto, o presente trabalho teve como objetivos estudar ações para acelerar a formação do horizonte A de um Latossolo Vermelho degradado, via adição de adubos verdes, lodo de esgoto e cultivo de uma espécie arbórea nativa de Cerrado, e selecionar indicadores para detectar as alterações da camada superficial do solo.

\section{MATERIAL E MÉTODOS}

O experimento foi realizado na Fazenda de Ensino e Pesquisa - Produção Animal, da Faculdade de Engenharia, campus de Ilha Solteira (UNESP), localizada no município de Selvíria, MS, à margem direita do rio Paraná. A área encontra-se nas coordenadas geográficas de $51^{\circ} 22$ ' de longitude oeste de Greenwich e $20^{\circ} 22^{\prime}$ de latitude sul, a $327 \mathrm{~m}$ de altitude, e apresenta médias anuais de: precipitação pluvial, $1.370 \mathrm{~mm}$; temperatura, $23,5^{\circ} \mathrm{C}$; e umidade relativa do ar, entre 70 e $80 \%$. O tipo climático, segundo Köppen, é Aw (clima tropical úmido, com estação chuvosa no verão e seca no inverno). O período chuvoso se estende de outubro a março; os meses de dezembro, janeiro e fevereiro constituem o trimestre mais chuvoso e os meses de junho, julho e agosto (média de $27 \mathrm{~mm}$ ), o trimestre mais seco. O relevo é suave a plano e o solo original é um Latossolo Vermelho distrófico (Demattê, 1980; Embrapa, 1999), muito profundo textura média (200-350 $\mathrm{g} \mathrm{kg}^{-1}$ de argila). Sua fração argila é de baixa atividade e constituída por gibbsita e caulinita (Demattê, 1980). O experimento foi realizado em área degradada, de onde foi retirada uma camada de solo de 8,60 m de espessura para utilização no terrapleno e fundação da Usina Hidrelétrica de Ilha Solteira, SP, a qual teve sua construção iniciada na década de 1960, e o solo decapitado, da área de estudo, está exposto desde 1969. Mesmo após a retirada dessa espessa camada de solo, este apresentou horizonte B remanescente, sobre o qual o experimento foi instalado. A vegetação nativa da área de estudo era o Cerrado.

O delineamento experimental adotado foi o de blocos completos casualizados, com seis tratamentos e cinco repetições, com parcelas de $150 \mathrm{~m}^{2}$ (15 x $\left.10 \mathrm{~m}\right)$. Os tratamentos objetivaram a recuperação da área e foram implantados em fevereiro de 2004, sendo eles: 1- testemunha - solo exposto (sem manejo); 2-vegetação nativa (Cerrado); 3- apenas espécie arbórea Astronium fraxinifolium (AF); 4- Astronium fraxinifolium + Canavalia ensiformis $(\mathrm{AF}+\mathrm{CE}) ; 5-$ Astronium fraxinifolium+Raphanus sativus (AF + RS); e 6Astronium fraxinifolium + Brachiaria decumbens + lodo de esgoto $\left(60 \mathrm{t} \mathrm{ha}^{-1}\right)(\mathrm{AF}+\mathrm{B}+\mathrm{LE})$. A dose de $60 \mathrm{t} \mathrm{ha}^{-1}$ foi definida levando-se em consideração a média das dosagens de lodo que têm sido utilizadas em pesquisas com recuperação de propriedades físicas dos solos (Pagliai et al., 1981; Jorge et al., 1991; Melo et al., 1994; Vaz \& Gonçalves, 2002). Na literatura sobre o tema, as doses variam de 20 a $120 \mathrm{t} \mathrm{ha}^{-1}$. De acordo com o quadro 1, onde constam as características químicas do lodo utilizado, as quantidades aplicadas, em $\mathrm{kg} \mathrm{ha}^{-1}$, de N, P e K foram, respectivamente, de 4.275,6; 1.127,40; e 908,4. Desse total, a quantidade de nutrientes disponíveis às plantas no primeiro ano estará, segundo Andreoli et al. (2001), em função de $30 \%$ da mineralização do N orgânico e de mais $30 \%$ de volatilização do $\mathrm{N}$ amoniacal, o que reduz cerca de um terço do $\mathrm{N}$ total aplicado ao solo. Quanto ao $\mathrm{P}$, poderá haver $70 \%$ de disponibilidade (Raij et al., 1997). Ressalta-se que o uso do lodo de esgoto teve como principal objetivo adicionar matéria orgânica ao solo e, ao mesmo tempo, dar um destino ao resíduo. Como este não apresentou problemas em sua composição com relação a metais pesados (Quadro 2), por ser de efluente predominantemente doméstico, a dose utilizada não estaria prejudicando o ambiente.

Optou-se pela espécie Astronium fraxinifolium, por ser esta nativa do Cerrado e de fácil produção de mudas em viveiro. Salienta-se que a espécie arbórea foi utilizada com o objetivo de recuperação da área, sem,

Quadro 1. Resultados da análise química (teores totais) do lodo de esgoto

\begin{tabular}{|c|c|c|c|c|c|c|c|c|c|c|c|c|}
\hline MO & $\mathbf{N}$ & $\mathbf{P}$ & $\mathbf{K}$ & $\mathbf{C a}$ & Mg & $\mathbf{S}$ & B & $\mathrm{Cu}$ & $\mathrm{Fe}$ & Mn & $\mathrm{Zn}$ & Umidade \\
\hline $\mathrm{g} \mathrm{dm}^{-3}$ & & & $\mathrm{~g} \mathrm{~kg}$ & & & & & & $\mathrm{mg} \mathrm{kg}^{-1}$ & & & $\mathrm{~kg} \mathrm{~kg}^{-1}$ \\
\hline 200 & 71,26 & 18,79 & 15,14 & 11,06 & 3,44 & 7,78 & 16,37 & 160,04 & 960,6 & 115,74 & 583,48 & 0,85 \\
\hline
\end{tabular}


Quadro 2. Análise química (teores totais) para fins de toxicidade do lodo de esgoto utilizado de Araçatuba-SP

\begin{tabular}{|c|c|c|}
\hline Parâmetro & Resultado & Limite máximo \\
\hline & \multicolumn{2}{|c|}{$\mathrm{mg} \mathrm{kg}^{-1}$} \\
\hline Alumínio & 0,100 & 0,200 \\
\hline Arsênio & nd & 0,050 \\
\hline Bário & 0,400 & 1,000 \\
\hline Cádmio & 0,004 & 0,005 \\
\hline Chumbo & 0,003 & 0,050 \\
\hline Cianeto & nd & 0,100 \\
\hline Cloretos & 39,000 & 250,000 \\
\hline Cobre & 0,040 & 1,000 \\
\hline Cromo Total & nd & 0,050 \\
\hline Dureza & 120,000 & 500,000 \\
\hline Fenol & nd & 0,001 \\
\hline Ferro Total & 2,860 & 0,300 \\
\hline Fluoretos & 0,640 & 1,500 \\
\hline Manganês & 0,300 & 0,100 \\
\hline Mercúrio & nd & 0,001 \\
\hline Nitrato & 4,700 & 10,000 \\
\hline Prata & 0,020 & 0,050 \\
\hline Selênio & nd & 0,010 \\
\hline Sulfato & 27,900 & 400,000 \\
\hline Sódio & 48,400 & 200,000 \\
\hline Surfatantes & nd & 0,200 \\
\hline Zinco & 3,640 & 5,000 \\
\hline
\end{tabular}

nd: não detectado. Método de análise baseado na $20^{\mathrm{a}}$ edição do "Standart Methods for the Examination of Water and Wastewater" Análises efetuadas segundo a NBR 10.004 - Resíduos Sólidos. Análises realizadas no Laboratório Labortechnic Tecnologia Ltda (www.labortec.com.br)

portanto, almejar explorar a silvicultura de forma racional e econômica. A combinação do tratamento 6 - Astronium fraxinifolium+Brachiaria decumbens + lodo de esgoto (60 t ha ${ }^{-1}$ ) justifica-se pelo fato de se estar utilizando uma espécie nativa de Cerrado, a gramínea, que é uma planta de rápido crescimento e pouco exigente, e o lodo de esgoto, que apresenta nutrientes orgânicos em formas facilmente mineralizadas. A hipótese é de que esta combinação levará à evolução mais rápida do horizonte A do solo decapitado (degradado). Outro fator do uso da gramínea é por estar numa região cuja atividade pecuária é a mais representativa.

O preparo da área constou de limpeza superficial, subsolagem e gradagens (aradora e niveladora) do solo, e aplicação de calcário dolomítico na dose de $2 \mathrm{t} \mathrm{ha-1,}$ exceto no tratamento 1 , que não recebeu nenhum tipo de manejo, e tratamento 2, que se trata da área com vegetação nativa de Cerrado. Nos tratamentos 3, 4, 5 e 6 foi implantada a espécie arbórea nativa de Cerrado, a Astronium fraxinifolium, com espaçamento entre as árvores de $3 \times 2 \mathrm{~m}$, portanto, 25 plantas por tratamento. Foram consideradas as nove plantas centrais para as avaliações. O lodo de esgoto utilizado foi obtido da Estação de Tratamento de Esgoto do município de Araçatuba-SP. Este efluente é predominantemente doméstico. O lodo foi espalhado manualmente e incorporado com grade aradora.

Para as análises físicas do solo, coletaram-se amostras indeformadas, com anel volumétrico com capacidade de $10^{-4} \mathrm{~m}^{3}$, em três sítios por parcela e em quatro camadas do solo: $0,00-0,05 ; 0,05-0,10$; 0,10-0,20; e 0,20-0,40 m (para a área degradada e para o solo de Cerrado). As propriedades físicas do solo analisadas foram: densidade do solo e porosidade total, pelo método do anel volumétrico; microporosidade, pelo método da mesa de tensão com coluna de água de $60 \mathrm{~cm}$; e macroporosidade, por diferença entre a porosidade total e a microporosidade. Todos os métodos foram realizados de acordo com Embrapa (1997) (Quadro 3). As amostras foram coletadas após um ano de implantação dos tratamentos.

As amostras para as análises químicas foram coletadas com o auxílio de trado de caneca nas mesmas camadas do solo, em cinco sítios por parcela, formando uma amostra composta, na mesma época em que foram coletadas as amostras para análise física do solo. As análises químicas do solo foram realizadas de acordo com o método descrito por Raij \& Quaggio (1983) e Raij et al. (2001), e foram avaliados os teores de P, $\mathrm{K}^{+}$, $\mathrm{Mg}^{2+}$ e $\mathrm{Ca}^{2+}$ pelo método de extração com resina trocadora de íons. O teor de matéria orgânica foi determinado pelo método colorimétrico e o $\mathrm{pH}$, em cloreto de cálcio, além da acidez potencial $(\mathrm{H}+\mathrm{Al})$ a $\mathrm{pH} 7,0$. Foram calculadas as somas de bases $(\mathrm{SB}=$ $\left.\mathrm{Ca}^{2+}+\mathrm{Mg}^{2+}+\mathrm{K}^{+}\right) \mathrm{CTC}$ total $(\mathrm{pH} 7,0)$ e saturação por bases (V) (Quadro 4). Tanto para as propriedades físicas como para as químicas, na análise estatística dos resultados trabalhou-se com a média das camadas de solo $(0,00-0,40 \mathrm{~m})$.

Os macrorganismos do solo foram avaliados após 18 meses de implantados os tratamentos, utilizandose o método de coleta direta, mediante o uso do quadrado metálico de $0,30 \mathrm{~m}$ de lado, o qual foi cravado no solo (Vidal \& Alves, 2003). As amostragens foram realizadas entre as linhas de plantio a $0,30 \mathrm{~m}$ do colo da planta. As amostras foram coletadas nas camadas de solo de $0,00-0,05 ; 0,05-0,10$; e $0,10-0,15 \mathrm{~m}$. A avaliação constou da contagem do número de indivíduos e da identificação da ordem. Para a análise dos resultados, trabalhou-se com a média das camadas de solo estudadas.

Em Astronium fraxinifolium, avaliaram-se a altura e o diâmetro de caule e, nos adubos verdes, a produção de massa de tecidos secos. Na massa seca foram coletadas plantas contidas em $1,00 \mathrm{~m}^{2}$, de dois pontos da área útil de cada parcela. A massa dos tecidos secos (estufa a $60-70{ }^{\circ} \mathrm{C}$ até atingir peso em equilíbrio) foi determinada, nos adubos verdes (plantas de cobertura), no período de florescimento pleno, pois essa é a época de seu manejo. No que se refere a Brachiaria decumbens, a avaliação foi realizada em três épocas no ano. 
Quadro 3. Características físicas do solo original (Cerrado) e degradado antes da implantação da pesquisa

Camada de solo Macroporosidade Microporosidade Porosidade total Densidade do solo

\begin{tabular}{|c|c|c|c|c|}
\hline \multirow{3}{*}{$\begin{array}{c}\mathrm{m} \\
0,00-0,05\end{array}$} & \multicolumn{3}{|c|}{$\mathrm{m}^{3} \mathrm{~m}^{-3}$} & \multirow[t]{2}{*}{$\mathrm{kg} \mathrm{dm}$} \\
\hline & \multicolumn{3}{|c|}{ Solo original (cerrado) } & \\
\hline & 0,17 & 0,23 & 0,40 & 1,43 \\
\hline $0,05-0,10$ & 0,16 & 0,25 & 0,40 & 1,45 \\
\hline $0,10-0,20$ & 0,18 & 0,22 & 0,40 & 1,47 \\
\hline \multirow[t]{2}{*}{$0,20-0,40$} & 0,18 & 0,22 & 0,40 & 1,42 \\
\hline & \multicolumn{4}{|c|}{ Solo degradado } \\
\hline $0,00-0,05$ & 0,06 & 0,28 & 0,34 & 1,63 \\
\hline $0,05-0,10$ & 0,06 & 0,26 & 0,32 & 1,77 \\
\hline $0,10-0,20$ & 0,07 & 0,29 & 0,36 & 1,78 \\
\hline $0,20-0,40$ & 0,06 & 0,23 & 0,29 & 1,89 \\
\hline
\end{tabular}

Quadro 4. Características químicas do solo original (Cerrado) e degradado antes da implantação da pesquisa

\begin{tabular}{|c|c|c|c|c|c|c|c|c|c|c|c|}
\hline Camada & $P$ resina & MO & $\begin{array}{c}\mathrm{pH} \\
\mathrm{CaCl}_{2}\end{array}$ & $\mathbf{K}^{+}$ & $\mathbf{C a}^{2+}$ & $\mathbf{M g}^{2+}$ & $\mathbf{H}+\mathbf{A l}$ & $\mathrm{Al}^{3+}$ & SB & CTC & $\mathbf{V}$ \\
\hline \multirow[t]{2}{*}{$\mathrm{m}$} & $\mathrm{mg} \mathrm{dm}{ }^{-3}$ & $\mathrm{~g} \mathrm{dm}^{-3}$ & & $\underline{-}$ & 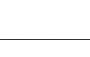 & 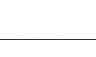 & $\mathrm{mol}_{\mathrm{c}} \mathrm{dm}$ & & & & $\%$ \\
\hline & \multicolumn{11}{|c|}{ Solo original (cerrado) } \\
\hline $0,00-0,05$ & 4 & 28 & 4,2 & 1,2 & 2 & 3 & 31 & 8 & 6,1 & 36,9 & 16 \\
\hline $0,05-0,10$ & 4 & 14 & 4,1 & 1,2 & 5 & 4 & 31 & 8 & 11,1 & 41,7 & 21 \\
\hline $0,10-0,20$ & 2 & 10 & 4,1 & 0,8 & 0 & 2 & 26 & 8 & 2,8 & 29,0 & 10 \\
\hline \multirow[t]{2}{*}{$0,20-0,40$} & 1 & 7 & 4,0 & 0,3 & 0 & 1 & 24 & 9 & 1,6 & 25,6 & 6 \\
\hline & \multicolumn{11}{|c|}{ Solo degradado } \\
\hline $0,00-0,05$ & 1 & 7 & 4,4 & 0,8 & 4 & 2 & 17 & 2 & 6,5 & 23,3 & 28 \\
\hline $0,05-0,10$ & 1 & 3 & 4,4 & 0,4 & 3 & 2 & 17 & 2 & 4,6 & 21,4 & 22 \\
\hline $0,10-0,20$ & 1 & 2 & 4,3 & 0,3 & 2 & 2 & 16 & 3 & 3,7 & 19,6 & 18 \\
\hline $0,20-0,40$ & 1 & 1 & 4,3 & 0,2 & 2 & 0 & 16 & 3 & 2,4 & 18,4 & 13 \\
\hline
\end{tabular}

Os resultados foram analisados efetuando-se a análise de variância e teste de Tukey para as comparações de média a $5 \%$. Também foram realizados contrastes entre a área de Cerrado e a testemunha (solo degradado), entre este e os tratamentos e entre os tratamentos, aplicando-se o teste F com o mesmo nível de significância. Trabalhou-se com a média dos resultados obtidos, considerando-se as quatro camadas de solos estudadas. Foi usado o software SAS (1990) para realização da análise estatística.

O monitoramento das alterações está sendo realizado anualmente, para uma proposta de cinco anos de pesquisa. Os indicadores selecionados para detectar alterações na camada superficial do solo, quer sejam qualitativos ou quantitativos, foram aqueles que mais se aproximaram das condições naturais do solo.

\section{RESULTADOS E DISCUSSÃO}

Houve diferença significativa entre os tratamentos para macro e microporosidade, porosidade total e densidade do solo. Contudo, observa-se que não houve diferença entre os tratamentos que visavam à recuperação das propriedades do solo (Quadro 5). Isso 
significa que até o momento estes estão agindo de forma semelhante quanto às alterações das propriedades físicas do solo, concordando com Alves \& Suzuki (2004). Segundo esses autores, as propriedades físicas de solos de Cerrado respondem lentamente à recuperação com plantas de cobertura. Verificou-se que o solo na testemunha está com condições físicas mais degradadas (macroporosidade menor, densidade do solo maior, porosidade total menor) comparadas às das parcelas experimentais que foram submetidas aos tratamentos, nos quais se teve por objetivo recuperar o solo, e também do solo original (Cerrado), com exceção da microporosidade.

Os valores de macroporosidade e porosidade total do solo foram maiores no Cerrado do que nos tratamentos de recuperação, enquanto a microporosidade e densidade do solo foram menores (Quadro 5). A redução da macroporosidade nos solos degradados decorre do aumento da sua compactação, que é evidenciada pelo aumento da densidade do solo (Araújo et al., 2004; Camilotti et al., 2005).

A densidade do solo estudado, nas condições naturais, está de acordo com valores verificados por Campos (2004). Verificaram-se, após um ano de implantados os tratamentos, valores que variaram de 1,56 a 1,59 $\mathrm{kg} \mathrm{dm}^{-3}$, sendo a condição da testemunha (sem tratamentos para recuperação) igual a $1,77 \mathrm{~kg} \mathrm{dm}^{-3}$. Reichert et al. (2003) consideram como densidade crítica, para o bom desenvolvimento do sistema radicular, valor igual a $1,55 \mathrm{~kg} \mathrm{dm}^{-3}$ para solos de textura média. Nesse caso, com a primeira análise dos resultados dos tratamentos utilizados para recuperação do solo, poderia se considerar a condição de densidade do solo adequada para desenvolvimento das plantas. O solo estudado, após um ano, vem demonstrando que está ocorrendo a recuperação de suas propriedades. Todavia, ressalta-se que, na combinação de prática mecânica (mobilização do solo) mais uso de matéria orgânica, o revolvimento foi o fator que sobressaiu, pois houve diferença na condição degradada para com as que receberam tratamento, e não houve diferenças entre os tratamentos que receberam somente o preparo do solo e preparo do solo mais a adição de matéria orgânica (adubo verde e lodo de esgoto). Esses resultados concordam com os observados por Jorge et al. (1991) e Melo et al. (2004), no que se refere ao uso de lodo de esgoto na recuperação de propriedades físicas do solo, pois esses autores observaram que quantidades até 50 t ha-1 não alteram a porosidade e a microporosidade do solo. Quanto ao fato de o uso da adubação verde também não ter apresentado diferença significativa, isso está de acordo com os resultados encontrados por Alves \& Suzuki (2004).

Houve diferença estatística entre os tratamentos no que se refere às propriedades químicas estudadas (Quadro 6). Como se pode observar, o tratamento com lodo de esgoto proporcionou aumento para $\mathrm{P}, \mathrm{H}+\mathrm{Al}$ e CTC. O tratamento em que o solo recebeu lodo de esgoto foi o que apresentou o maior teor de P; o mesmo foi observado por Galdos et al. (2004) no seu primeiro ano de experimento. A aplicação de lodo de esgoto funcionou como uma adubação corretiva, elevando os teores baixos até valores muito altos. Todavia, sua aplicação, de forma a aumentar o $\mathrm{P}$ no solo, até valores tão altos deve ser cautelosa em áreas suscetíveis ao escoamento superficial, pois pode provocar contaminação de cursos de água (Tamanini, 2004). Em se tratando dos demais tratamentos, não houve diferença para o teor de P.

Quadro 5. Valores médios das propriedades físicas do solo, para a camada de 0,00-0,40 m, obtidos para os tratamentos estudados

Tratamento Macroporosidade Microporosidade Porosidade total Densidade do solo

\begin{tabular}{|c|c|c|c|c|c|c|c|c|}
\hline \multirow[b]{2}{*}{ Testemunha } & \multicolumn{6}{|c|}{$\mathrm{m}^{3} \mathrm{~m}^{-3}$} & \multicolumn{2}{|c|}{$\mathrm{kg} \mathrm{dm}^{-3}$} \\
\hline & 0,06 & $\mathrm{C}$ & 0,27 & $\mathrm{~A}$ & 0,33 & $\mathrm{C}$ & 1,77 & $\mathrm{~A}$ \\
\hline Cerrado & 0,17 & $\mathrm{~A}$ & 0,23 & $\mathrm{~B}$ & 0,40 & $\mathrm{~A}$ & 1,44 & $\mathrm{C}$ \\
\hline $\mathrm{AF}$ & 0,10 & B & 0,27 & $\mathrm{~A}$ & 0,37 & $\mathrm{ABC}$ & 1,56 & $\mathrm{BC}$ \\
\hline $\mathrm{AF}+\mathrm{CE}$ & 0,08 & $\mathrm{BC}$ & 0,29 & $\mathrm{~A}$ & 0,37 & $\mathrm{ABC}$ & 1,58 & B \\
\hline $\mathrm{AF}+\mathrm{RS}$ & 0,09 & $\mathrm{BC}$ & 0,28 & $\mathrm{~A}$ & 0,37 & $\mathrm{AB}$ & 1,59 & B \\
\hline $\mathrm{AF}+\mathrm{B}+\mathrm{LE}$ & 0,08 & $\mathrm{BC}$ & 0,27 & $\mathrm{~A}$ & 0,35 & $\mathrm{BC}$ & 1,58 & B \\
\hline CV (\%) & \multicolumn{2}{|c|}{37,9} & \multicolumn{2}{|c|}{13,7} & \multicolumn{2}{|c|}{12,0} & \multicolumn{2}{|c|}{9,2} \\
\hline DMS & \multicolumn{2}{|c|}{0,034} & \multicolumn{2}{|c|}{0,034} & \multicolumn{2}{|c|}{0,040} & \multicolumn{2}{|c|}{0,134} \\
\hline
\end{tabular}

AF: Astronium fraxinifolium. AF + CE: Astronium fraxinifolium + Canavalia ensiformis. AF + RS: Astronium fraxinifolium + Raphanus sativus. AF + B + LE: Astronium fraxinifolium + Brachiaria decumbens + lodo de esgoto. Médias seguidas de letras iguais na coluna não diferem entre si pelo teste de Tukey a $5 \%$. 
Quadro 6. Valores médios das propriedades químicas do solo, para a camada de 0,00-0,40 m, obtidos para os tratamentos estudados

\begin{tabular}{|c|c|c|c|c|c|c|c|c|c|c|c|}
\hline Tratamento & P resina & MO & $\begin{array}{c}\mathrm{pH} \\
\mathrm{CaCl}_{2}\end{array}$ & $\mathbf{K}^{+}$ & $\mathrm{Ca}^{2+}$ & $\mathrm{Mg}^{2+}$ & $\mathbf{H}+\mathbf{A l}$ & $\mathrm{Al}^{3+}$ & SB & CTC & V \\
\hline & $\mathrm{mg} \mathrm{dm}^{-3}$ & $\mathrm{~g} \mathrm{dm}^{-3}$ & & & 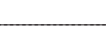 & $n$ & $\mathrm{~mol}_{\mathrm{c}} \mathrm{dm}^{-3}$ & 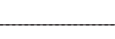 & & 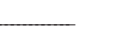 & $\%$ \\
\hline Testemunha & $1,2 \mathrm{~B}$ & $2,8 \mathrm{~B}$ & $4,6 \mathrm{~B}$ & $0,7 \mathrm{~A}$ & $2,5 \mathrm{~B}$ & $2,0 \mathrm{D}$ & $14,5 \mathrm{CB}$ & $1,4 \mathrm{~B}$ & $4,9 \mathrm{~B}$ & $19,3 \mathrm{E}$ & $24,4 \mathrm{C}$ \\
\hline Cerrado & $2,5 \mathrm{~B}$ & $15,5 \mathrm{~A}$ & $4,2 \mathrm{C}$ & $0,6 \mathrm{BA}$ & $3,0 \mathrm{~B}$ & $3,2 \mathrm{CD}$ & $29,0 \mathrm{~A}$ & $6,2 \mathrm{~A}$ & $6,7 \mathrm{~B}$ & $35,7 \mathrm{~A}$ & $16,0 \mathrm{C}$ \\
\hline $\mathrm{AF}$ & $1,1 \mathrm{~B}$ & $2,8 \mathrm{~B}$ & $5,5 \mathrm{~A}$ & $0,4 \mathrm{BA}$ & $8,7 \mathrm{~A}$ & $3,8 \mathrm{BCD}$ & $11,4 \mathrm{D}$ & $0,4 \mathrm{C}$ & $12,7 \mathrm{~A}$ & $24,2 \mathrm{DE}$ & $48,2 \mathrm{AB}$ \\
\hline $\mathrm{AF}+\mathrm{CE}$ & $1,2 \mathrm{~B}$ & $2,6 \mathrm{~B}$ & $5,6 \mathrm{~A}$ & $0,3 \mathrm{~B}$ & $11,5 \mathrm{~A}$ & $5,8 \mathrm{~A}$ & $11,6 \mathrm{CD}$ & $0,8 \mathrm{CB}$ & $17,7 \mathrm{~A}$ & $29,3 \mathrm{BC}$ & $51,2 \mathrm{~A}$ \\
\hline $\mathrm{AF}+\mathrm{RS}$ & $1,0 \mathrm{~B}$ & $1,9 \mathrm{~B}$ & $5,5 \mathrm{~A}$ & $0,4 \mathrm{BA}$ & $8,7 \mathrm{~A}$ & $4,2 \mathrm{ABC}$ & $11,6 \mathrm{CD}$ & $0,9 \mathrm{CB}$ & $13,2 \mathrm{~A}$ & $24,8 \mathrm{CD}$ & $45,4 \mathrm{AB}$ \\
\hline $\mathrm{AF}+\mathrm{B}+\mathrm{LE}$ & $90,0 \mathrm{~A}$ & $5,4 \mathrm{~B}$ & $4,8 \mathrm{~B}$ & $0,7 \mathrm{BA}$ & $8,4 \mathrm{~A}$ & $5,3 \mathrm{AB}$ & $17,4 \mathrm{~B}$ & $1,1 \mathrm{~B}$ & $17,4 \mathrm{~A}$ & $31,7 \mathrm{AB}$ & $41,2 \mathrm{~B}$ \\
\hline CV (\%) & 58,3 & 75,3 & 8,67 & 76,0 & 53,0 & 51,6 & 20,0 & 44,2 & 47,5 & 19,5 & 27,5 \\
\hline DMS & 31,297 & 3,597 & 0,402 & 0,352 & 3,494 & 1,920 & 2,936 & 0,735 & 5,088 & 4,959 & 9,571 \\
\hline
\end{tabular}

AF: Astronium fraxinifolium. AF + CE: Astronium fraxinifolium + Canavalia ensiformis. AF + RS: Astronium fraxinifolium + Raphanus sativus. AF + B + LE: Astronium fraxinifolium + Brachiaria decumbens + lodo de esgoto. Médias seguidas de letras iguais na coluna não diferem entre si pelo teste de Tukey a $5 \%$.

Todos os tratamentos de recuperação e a testemunha diferiram estatisticamente do Cerrado no que se refere ao teor de matéria orgânica, porém observa-se efeito promissor do tratamento Brachiaria decumbens com lodo de esgoto. O aumento no teor de matéria orgânica em solo onde foi aplicado o lodo de esgoto foi observado por Galdos et al. (2004). Melo et al. (1994) encontraram aumento de carbono orgânico com aplicação de lodo de esgoto apenas na dose mais elevada (32 t ha ${ }^{-1}$ ) até 230 dias após aplicação.

Quanto ao pH (Quadro 6), verificou-se que naturalmente o solo apresenta acidez muito alta. Nos tratamentos de recuperação do solo, devido à calagem, o pH aumentou, com exceção do tratamento que recebeu lodo de esgoto, pois neste caso o $\mathrm{pH}$ foi menor em relação aos tratamentos que receberam calcário. Esse efeito pode ser explicado pelo fato de o lodo de esgoto utilizado não ser tratado com cal e também pelo poder acidificante gerado pela biodecomposição da matéria orgânica (Camargo et al., 1999; Franchini et al., 2001).

$\mathrm{O} \mathrm{K}^{+}$foi significativamente diferente entre os tratamentos, permanecendo estável em teores considerados baixos. Esses teores de $\mathrm{K}^{+}$observados estão semelhantes aos verificados no trabalho realizado por Silva et al. (1998, 2001), que estudaram a recuperação de uma área degradada por mineração de calcário com o uso de lodo de esgoto. Simonete et al. (2003) ressaltaram a ocorrência da baixa concentração desse elemento no lodo de esgoto, sendo necessária sua complementação, visando atender às necessidades das plantas. Em relação aos teores de $\mathrm{Ca}^{2+}$, os tratamentos de recuperação não diferiram entre si; apenas diferiram do Cerrado e testemunha. Essa semelhança entre os tratamentos pode indicar que apenas a realização da calagem foi suficiente para melhoria das condições químicas do solo. Tamanini et al. (2004) obtiveram resultados semelhantes. Houve diferença no teor de $\mathrm{Mg}^{2+}$ entre os tratamentos $\mathrm{AF}+\mathrm{CE}$ e AF. O uso do adubo verde provavelmente contribuiu para extração e ciclagem do $\mathrm{Mg}$ no solo, concordando com resultados verificados por Nascimento et al. (2003).

$\mathrm{O} \mathrm{H}+\mathrm{Al}$ aumentou no tratamento que recebeu lodo de esgoto e diminuiu nos demais tratamentos de recuperação, comparados à testemunha (Quadro 6). Não houve diferença significativa da SB (Quadro 6) entre os tratamentos de recuperação apenas em relação à testemunha e ao Cerrado, que não receberam a calagem. Pode-se observar que os atributos indicativos da reação do solo diferiram com a correção da acidez, com o aumento do pH e soma de bases e diminuição do $\mathrm{Al}$ nos tratamentos onde o calcário foi adicionado, concordando com Camargo et al. (1997) e Miranda et al. (2005).

Houve diferença nos valores de CTC e V. Entre os tratamentos usados para recuperação do solo, o mais promissor, quanto às mudanças na CTC, foi o $\mathrm{AF}+\mathrm{B}+\mathrm{LE}$, provavelmente devido ao aporte de resíduo orgânico (lodo de esgoto mais braquiária); e, para o V, os tratamentos receberam a calagem, diferindo, portanto, da testemunha e da área de Cerrado.

De modo geral, os gêneros de macrorganismos mais representativos encontrados no ambiente nativo (Cerrado) foram formigas e cupins (Figura 1). Por outro lado, tanto no solo degradado como no ambiente em recuperação não foi encontrado cupim. Já as formigas foram encontradas em todos os ambientes. Vale salientar que há grande número de indivíduos na fase larval do tipo escarabeiforme, principalmente 
nos tratamentos onde foram cultivados o Astronium fraxinifolium com a Brachiaria decumbens + lodo de esgoto ou nos tratamentos com apenas a adubação verde. Isso indica que o manejo adotado está sendo eficaz na recuperação da macrofauna estudada, na respectiva profundidade. Segundo Uzêda (1999) e Takeda (1995), esse comportamento pode ser explicado pela presença da Brachiaria decumbens, pois esta destaca-se por apresentar forte aumento no número de indivíduos epigeicos, ou seja, espécies que vivem e se alimentam na superfície e que possuem atuação sobre a liberação dos nutrientes, possivelmente em função da cobertura morta, que torna mais adequado o ambiente (temperatura e umidade) e fornece alimento a esses indivíduos.

Quanto à diversidade da macrofauna, não foram observadas diferenças entre tratamentos, porém o número de indivíduos foi maior no tratamento $\mathrm{AF}+\mathrm{B}+\mathrm{LE}$. Na manutenção e melhoria das condições físicas internas e externas do solo, a adição e o balanço da matéria orgânica são fundamentais, pois essa manutenção e melhoria só poderão ser alcançadas e mantidas por via biológica, isto é, por meio da ação de raízes, da atividade macro e microbiana e da decomposição da matéria orgânica (Alves, 2001). Segundo Merlim (2005), o monitoramento da macrofauna demonstrou ser uma excelente estratégia como indicadora da qualidade do ambiente, pela sua abundância relativa e diversidade de grupos da fauna edáfica.

Observou-se diferença significativa entre os dados de altura e diâmetro de plantas de Astronium fraxinifolium obtidos nos diferentes tratamentos (Quadro 7). O tratamento AF + B + LE favoreceu o crescimento e o desenvolvimento das plantas, enquanto os demais tratamentos não diferiram entre si.

O rendimento de material seco da Brachiaria decumbens (Quadro 8), aos 88 dias, foi baixo devido às condições de estiagem e do solo degradado. Paulino et al. (1995) verificaram por corte da Brachiaria decumbens, após 89 dias de cultivo, a produção de

\section{Testemunha}

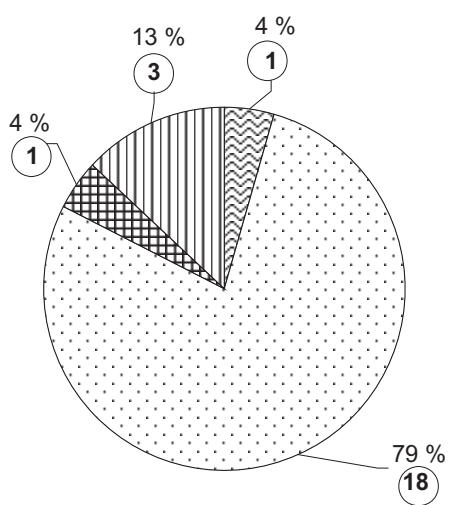

$\mathbf{A F}+\mathbf{C E}$

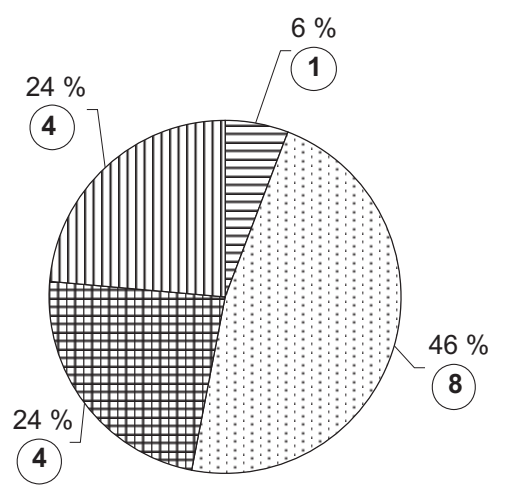

图 besouro
E aranha

III pupa
Cerrado

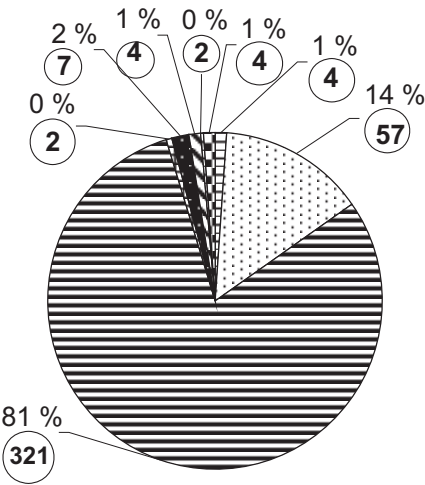

$\mathbf{A F}+\mathbf{R S}$

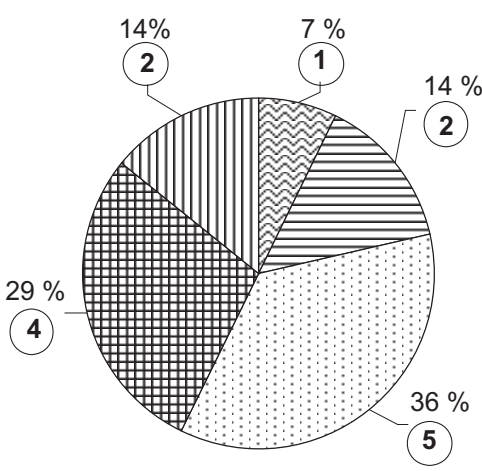

臣 minhoca

目 cupim
Astronium fraxinifolium
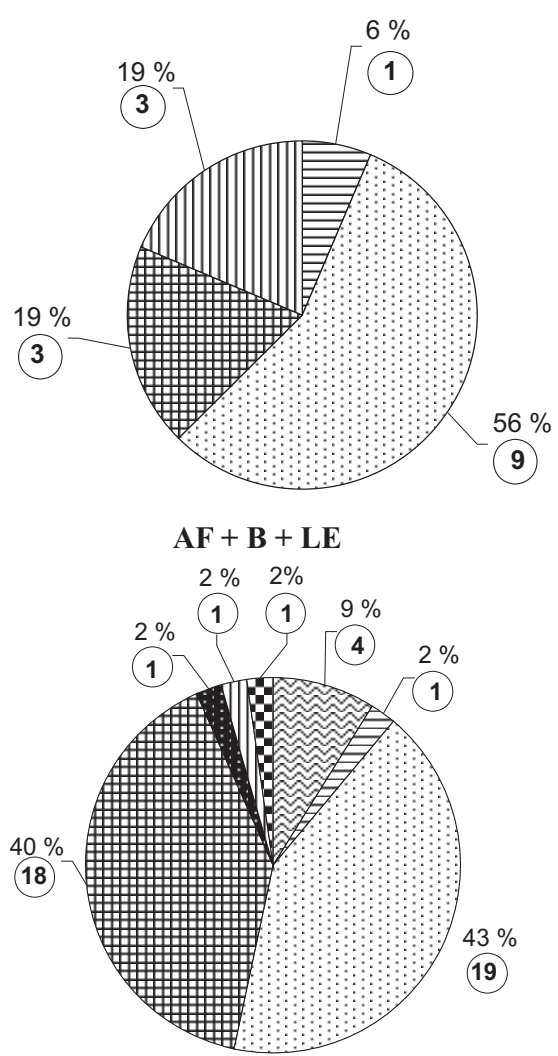

曲 larva tesourinha

$[\cdot]$ formiga

barata

Figura 1. Distribuição dos macrorganismos coletados do solo nos diferentes tratamentos. Legenda: números contidos nos círculos são referentes ao número absoluto de macrorganismos. Astronium fraxinifolium + Canavalia ensiformis (AF + CE); Astronium fraxinifolium + Raphanus sativus (AF + RS); Astronium fraxinifolium + Brachiaria decumbens+lodo de esgoto (AF + B + LE). 
Quadro 7. Valores médios de altura, diâmetro e sobrevivência de plantas de Astronium fraxinifolium, nos tratamentos estudados, aos 494 dias após a implantação dos tratamentos

\begin{tabular}{lcc}
\hline Tratamento & Altura & Diâmetro \\
\hline & $\mathrm{m}$ & $\mathrm{cm}$ \\
$\mathrm{AF}$ & $0,30 \mathrm{~B}$ & $1,42 \mathrm{~B}$ \\
$\mathrm{AF}+\mathrm{CE}$ & $0,41 \mathrm{~B}$ & $1,36 \mathrm{~B}$ \\
$\mathrm{AF}+\mathrm{RS}$ & $0,42 \mathrm{~B}$ & $1,38 \mathrm{~B}$ \\
$\mathrm{AF}+\mathrm{B}+\mathrm{LE}$ & $1,04 \mathrm{~A}$ & $3,10 \mathrm{~A}$ \\
\hline
\end{tabular}

Médias seguidas de letras iguais na coluna diferem entre si pelo teste de Tukey a $5 \%$.

Quadro 8. Matéria seca da Brachiaria decumbens e Canavalia ensiformes avaliada em várias épocas

\begin{tabular}{lcr}
\hline \multicolumn{1}{c}{ Adubo verde } & $\begin{array}{c}\text { Época de } \\
\text { avaliação }\end{array}$ & $\begin{array}{c}\text { Matéria } \\
\text { seca }\end{array}$ \\
\hline & & $\mathrm{kg} \mathrm{ha}^{-1}$ \\
Brachiaria decumbens $(2004)$ & 88 dias & 366 \\
Brachiaria decumbens $(2004)$ & 274 dias & 10.133 \\
Brachiaria decumbens $(2005)$ & 476 dias & 4.255 \\
Canavalia ensiformis $(2004)$ & 88 dias & 352 \\
Canavalia ensiformis $(2005)$ & 74 dias & 886 \\
\hline
\end{tabular}

$5.000 \mathrm{~kg} \mathrm{ha}^{-1}$. Já Alves (2001), em um solo em recuperação há sete anos, verificou produção de $7.000 \mathrm{~kg} \mathrm{ha}^{-1}$, porém sem haver corte da fitomassa no ano. Portanto, analisando os resultados referentes e massa acumulada após 274 dias, nota-se que o solo está respondendo às ações de recuperação. Da mesma forma, Canavalia ensiformes, no segundo ano produziu 2,5 vezes mais massa. Quanto a Raphanus sativus, não foi possível avaliar a massa de tecido seco, pois, apesar de ter tido boa germinação, não cresceu até o período previsto para avaliação.

Com relação aos contrastes entre tratamentos (Quadro 9), houve significância entre o tratamento 1 (testemunha) e os demais. Isso significa que as propriedades físicas do solo degradado estão sendo recuperadas. Por outro lado, no contraste do tratamento 2 Cerrado $\mathrm{x}$ demais tratamentos, os que obtiveram resultados não-significativos correspondem aos tratamentos que tiveram o melhor desempenho, ou seja, foram os que se aproximaram das condições naturais do solo estudado.

Verificou-se que entre o tratamento 1 e os demais houve diferença significativa para macroporosidade, porosidade total e densidade do solo; para o tratamento 2 e os demais, houve diferença para todas as propriedades físicas do solo estudadas (Quadro 9). No desdobramento da análise dos contrastes da testemunha com os tratamentos de recuperação, podese observar que os contrastes 1 x 3 e 1 x 5 foram os que obtiveram maiores alterações das propriedades físicas. Isso pode ser explicado em razão de ser menor o número de vezes de entrada de máquinas $\mathrm{e}$ implementos nos tratamentos 3 e 5 , enquanto nos demais tratamentos as operações mecânicas foram mais intensivas (para semear e roçar). No contraste do tratamento $1 \mathrm{x}$ demais, a densidade do solo foi a propriedade física que apresentou diferença significativa para os quatro contrastes.

Quanto ao desdobramento da análise dos resultados do Cerrado com os tratamentos de recuperação, podese observar pelo contraste $2 \times 3$, que foi o que apresentou as propriedades físicas mais próximas da condição nativa do Cerrado, significando que este, até o momento, é o melhor tratamento para recuperação das propriedades físicas do solo, em curto prazo. Nos contrastes $2 \times 3,2 \times 4$ e $2 \times 5$ a porosidade total não foi significativa e, no $2 \times 3$, além da porosidade total, a densidade do solo também não foi. Isso significa que a porosidade total foi eficaz para detectar as mudanças na comparação do solo em recuperação com a condição de Cerrado. O tratamento Astronium fraxinifolium + Brachiaria decumbens + lodo de esgoto não foi o mais eficaz na recuperação das propriedades físicas, conforme o esperado. Provavelmente, o número de entradas de máquinas e implementos (para incorporar lodo, para semear e para roçar Brachiaria decumbens), em curto prazo, tenha prejudicado as propriedades físicas do solo, esperando-se que em longo prazo haja compensação devido ao aporte da matéria orgânica e, conseqüente-mente, à melhoria das propriedades físicas.

Não houve significância estatística para os contrastes entre o tratamento 1 e os demais, para $P$, $\mathrm{K}, \mathrm{H}+\mathrm{Al}$ e Al; entre os contrastes do tratamento $2 \mathrm{e}$ os demais, não houve diferença para $\mathrm{P}, \mathrm{K}, \mathrm{Mg}$ e SB. No desdobramento da análise dos contrastes da testemunha com os demais tratamentos de recuperação, pode-se observar que o comportamento foi semelhante. Em todos os contrastes do tratamento 1, o $\mathrm{H}+\mathrm{Al}$ e a CTC foram significativos. Quando desconsiderado o contraste 1 x $2, \mathrm{o} \mathrm{pH}, \mathrm{Ca}, \mathrm{Mg}, \mathrm{SB}$, $\mathrm{H}+\mathrm{Al}, \mathrm{SB}$, CTC e V foram os que apresentaram maior número de significância entre os contrastes, evidenciando serem os melhores indicadores das alterações químicas do solo, ou seja, o $\mathrm{P}, \mathrm{MO}, \mathrm{Ke} \mathrm{Al}$ foram os menos adequados como indicadores da qualidade do solo, em curto prazo, quanto às alterações das propriedades químicas.

Nos contrastes entre os tratamentos de recuperação, as alterações nos tratamentos $\mathrm{AF}+\mathrm{CE}$ $\mathrm{e} \mathrm{AF}+\mathrm{B}+\mathrm{LE}$ indicaram as propriedades químicas do solo mais significativas. Em primeiro lugar, pelo 
Quadro 9. Teste de significância para os contrastes entre os tratamentos referentes às propriedades do solo estudadas

\begin{tabular}{|c|c|c|c|c|c|c|c|c|c|c|c|c|c|c|c|c|c|}
\hline \multirow{2}{*}{ Propriedade } & \multicolumn{17}{|c|}{ Contrastes } \\
\hline & 1xdemais & $2 x d e m a i s$ & $1 \times 2$ & $1 \times 3$ & $1 \times 4$ & $1 \times 5$ & $1 \times 6$ & $2 \times 3$ & $2 \times 4$ & $2 \times 5$ & $2 \times 6$ & $3 \times 4$ & $3 \times 5$ & $3 \times 6$ & $4 \times 5$ & $4 \times 6$ & $5 \times 6$ \\
\hline & \multicolumn{17}{|c|}{ Propriedades físicas } \\
\hline Macroporosidade & * & * & * & * & $\mathrm{ns}$ & $\mathrm{ns}$ & $\mathrm{ns}$ & * & * & * & * & $\mathrm{ns}$ & $\mathrm{ns}$ & $\mathrm{ns}$ & $\mathrm{ns}$ & $\mathrm{ns}$ & $\mathrm{ns}$ \\
\hline Microporosidade & $\mathrm{ns}$ & * & * & $\mathrm{ns}$ & $\mathrm{ns}$ & $\mathrm{ns}$ & $\mathrm{ns}$ & * & * & * & * & $\mathrm{ns}$ & $\mathrm{ns}$ & $\mathrm{ns}$ & $\mathrm{ns}$ & $\mathrm{ns}$ & $\mathrm{ns}$ \\
\hline Porosidade Total & $*$ & * & * & $\mathrm{ns}$ & $\mathrm{ns}$ & * & $\mathrm{ns}$ & $\mathrm{ns}$ & $\mathrm{ns}$ & $\mathrm{ns}$ & * & $\mathrm{ns}$ & $\mathrm{ns}$ & $\mathrm{ns}$ & $\mathrm{ns}$ & $\mathrm{ns}$ & $\mathrm{ns}$ \\
\hline \multirow[t]{2}{*}{ Densidade do solo } & * & $*$ & * & $*$ & $*$ & $*$ & $*$ & $\mathrm{~ns}$ & $*$ & $*$ & * & $\mathrm{ns}$ & $\mathrm{ns}$ & $\mathrm{ns}$ & $\mathrm{ns}$ & $\mathrm{ns}$ & $\mathrm{ns}$ \\
\hline & \multicolumn{17}{|c|}{ Propriedades químicas } \\
\hline $\mathrm{P}$ & $\mathrm{ns}$ & $\mathrm{ns}$ & $\mathrm{ns}$ & $\mathrm{ns}$ & $\mathrm{ns}$ & $\mathrm{ns}$ & $\mathrm{ns}$ & $\mathrm{ns}$ & $\mathrm{ns}$ & $\mathrm{ns}$ & * & $\mathrm{ns}$ & $\mathrm{ns}$ & * & $\mathrm{ns}$ & * & $*$ \\
\hline MO & $*$ & $*$ & $*$ & $\mathrm{~ns}$ & $\mathrm{~ns}$ & $\mathrm{~ns}$ & $\mathrm{~ns}$ & $*$ & $*$ & $*$ & * & $\mathrm{ns}$ & $\mathrm{ns}$ & $\mathrm{ns}$ & $\mathrm{ns}$ & $\mathrm{ns}$ & $\mathrm{ns}$ \\
\hline $\mathrm{pH}$ & * & * & $\mathrm{ns}$ & $*$ & $*$ & $*$ & $\mathrm{~ns}$ & * & * & * & * & $\mathrm{ns}$ & $\mathrm{ns}$ & * & $\mathrm{ns}$ & $*$ & $*$ \\
\hline $\mathrm{K}$ & $\mathrm{ns}$ & $\mathrm{ns}$ & $\mathrm{ns}$ & $*$ & * & $\mathrm{ns}$ & $\mathrm{ns}$ & $\mathrm{ns}$ & $\mathrm{ns}$ & $\mathrm{ns}$ & $\mathrm{ns}$ & $\mathrm{ns}$ & $\mathrm{ns}$ & $\mathrm{ns}$ & $\mathrm{ns}$ & $*$ & $\mathrm{~ns}$ \\
\hline $\mathrm{Ca}$ & $*$ & $*$ & $\mathrm{~ns}$ & * & * & $*$ & * & $*$ & $*$ & $*$ & $*$ & $\mathrm{~ns}$ & $\mathrm{~ns}$ & $\mathrm{~ns}$ & $\mathrm{~ns}$ & $\mathrm{~ns}$ & $\mathrm{~ns}$ \\
\hline $\mathrm{Mg}$ & * & $\mathrm{ns}$ & $\mathrm{ns}$ & $\mathrm{ns}$ & * & $*$ & $*$ & $\mathrm{~ns}$ & * & $\mathrm{ns}$ & * & * & $\mathrm{ns}$ & $\mathrm{ns}$ & $\mathrm{ns}$ & $\mathrm{ns}$ & $\mathrm{ns}$ \\
\hline $\mathrm{H}+\mathrm{Al}$ & $\mathrm{ns}$ & $*$ & $*$ & $*$ & * & * & $*$ & $*$ & * & $*$ & * & $\mathrm{ns}$ & $\mathrm{ns}$ & $*$ & $\mathrm{~ns}$ & $*$ & $*$ \\
\hline $\mathrm{Al}$ & $\mathrm{ns}$ & $*$ & * & * & $\mathrm{ns}$ & $\mathrm{ns}$ & $\mathrm{ns}$ & $*$ & * & * & $*$ & $\mathrm{~ns}$ & $\mathrm{~ns}$ & $*$ & $\mathrm{~ns}$ & $\mathrm{~ns}$ & $\mathrm{~ns}$ \\
\hline $\mathrm{SB}$ & $*$ & $\mathrm{~ns}$ & $\mathrm{~ns}$ & * & $*$ & $*$ & $*$ & * & * & * & * & * & $\mathrm{ns}$ & $\mathrm{ns}$ & $\mathrm{ns}$ & $\mathrm{ns}$ & $\mathrm{ns}$ \\
\hline $\mathrm{CTC}$ & * & $*$ & $*$ & * & * & $*$ & * & * & * & * & $\mathrm{ns}$ & $*$ & $\mathrm{~ns}$ & * & $\mathrm{ns}$ & $\mathrm{ns}$ & $*$ \\
\hline \multirow[t]{2}{*}{$\mathrm{V} \%$} & * & $*$ & $\mathrm{~ns}$ & * & * & $*$ & * & * & * & * & * & $\mathrm{ns}$ & $\mathrm{ns}$ & $\mathrm{ns}$ & $\mathrm{ns}$ & $*$ & $\mathrm{~ns}$ \\
\hline & \multicolumn{17}{|c|}{ Macrorganismos } \\
\hline Larva & $\mathrm{ns}$ & $\mathrm{ns}$ & $\mathrm{ns}$ & ns & $\mathrm{ns}$ & $\mathrm{ns}$ & * & $\mathrm{ns}$ & $\mathrm{ns}$ & $\mathrm{ns}$ & * & $\mathrm{ns}$ & $\mathrm{ns}$ & * & $\mathrm{ns}$ & $\mathrm{ns}$ & $\mathrm{ns}$ \\
\hline Formiga & $\mathrm{ns}$ & $\mathrm{ns}$ & $\mathrm{ns}$ & $\mathrm{ns}$ & $\mathrm{ns}$ & $\mathrm{ns}$ & $\mathrm{ns}$ & * & $*$ & $*$ & $\mathrm{~ns}$ & $\mathrm{~ns}$ & $\mathrm{~ns}$ & $\mathrm{~ns}$ & $\mathrm{~ns}$ & $\mathrm{~ns}$ & $\mathrm{~ns}$ \\
\hline Besouro & $\mathrm{ns}$ & $\mathrm{ns}$ & $\mathrm{ns}$ & $\mathrm{ns}$ & $\mathrm{ns}$ & $\mathrm{ns}$ & $\mathrm{ns}$ & $\mathrm{ns}$ & $\mathrm{ns}$ & $\mathrm{ns}$ & $*$ & $\mathrm{~ns}$ & $\mathrm{~ns}$ & $*$ & $\mathrm{~ns}$ & $*$ & $\mathrm{~ns}$ \\
\hline Aranha & $\mathrm{ns}$ & $\mathrm{ns}$ & $\mathrm{ns}$ & $\mathrm{ns}$ & $\mathrm{ns}$ & $\mathrm{ns}$ & $\mathrm{ns}$ & $\mathrm{ns}$ & $\mathrm{ns}$ & ns & $\mathrm{ns}$ & $\mathrm{ns}$ & $\mathrm{ns}$ & $\mathrm{ns}$ & $\mathrm{ns}$ & $\mathrm{ns}$ & $\mathrm{ns}$ \\
\hline Cupim & $\mathrm{ns}$ & $*$ & * & $\mathrm{ns}$ & $\mathrm{ns}$ & $\mathrm{ns}$ & $\mathrm{ns}$ & * & * & * & * & $\mathrm{ns}$ & $\mathrm{ns}$ & $\mathrm{ns}$ & $\mathrm{ns}$ & $\mathrm{ns}$ & $\mathrm{ns}$ \\
\hline Centopéia & $\mathrm{ns}$ & * & * & $\mathrm{ns}$ & $\mathrm{ns}$ & $\mathrm{ns}$ & $\mathrm{ns}$ & * & * & * & * & $\mathrm{ns}$ & $\mathrm{ns}$ & $\mathrm{ns}$ & $\mathrm{ns}$ & $\mathrm{ns}$ & $\mathrm{ns}$ \\
\hline Barata & $\mathrm{ns}$ & * & * & $\mathrm{ns}$ & $\mathrm{ns}$ & $\mathrm{ns}$ & $\mathrm{ns}$ & $\mathrm{ns}$ & $\mathrm{ns}$ & $\mathrm{ns}$ & $\mathrm{ns}$ & $\mathrm{ns}$ & $\mathrm{ns}$ & $\mathrm{ns}$ & $\mathrm{ns}$ & $\mathrm{ns}$ & $\mathrm{ns}$ \\
\hline Pupa & $\mathrm{ns}$ & $\mathrm{ns}$ & $\mathrm{ns}$ & $\mathrm{ns}$ & $\mathrm{ns}$ & $\mathrm{ns}$ & $\mathrm{ns}$ & $\mathrm{ns}$ & $\mathrm{ns}$ & $\mathrm{ns}$ & $\mathrm{ns}$ & $\mathrm{ns}$ & $\mathrm{ns}$ & $\mathrm{ns}$ & $\mathrm{ns}$ & $\mathrm{ns}$ & $\mathrm{ns}$ \\
\hline Tesourinha & ns & $\mathrm{ns}$ & $\mathrm{ns}$ & $\mathrm{ns}$ & $\mathrm{ns}$ & $\mathrm{ns}$ & $\mathrm{ns}$ & $\mathrm{ns}$ & $\mathrm{ns}$ & ns & $\mathrm{ns}$ & $\mathrm{ns}$ & $\mathrm{ns}$ & $\mathrm{ns}$ & $\mathrm{ns}$ & $\mathrm{ns}$ & $\mathrm{ns}$ \\
\hline Minhoca & $\mathrm{ns}$ & * & $\mathrm{ns}$ & $\mathrm{ns}$ & $\mathrm{ns}$ & $\mathrm{ns}$ & $\mathrm{ns}$ & $\mathrm{ns}$ & $\mathrm{ns}$ & $\mathrm{ns}$ & $\mathrm{ns}$ & $\mathrm{ns}$ & $\mathrm{ns}$ & $\mathrm{ns}$ & $\mathrm{ns}$ & $\mathrm{ns}$ & $\mathrm{ns}$ \\
\hline
\end{tabular}

1: testemunha, 2: Cerrado, 3: Astronium fraxinifolium, 4: Astronium fraxinifolium + Canavalia ensiformis, 5: Astronium fraxinifolium + Rafanus sativus e 6: Astronium fraxinifolium + Brachiaria decumbens + Lodo de esgoto. *: significativo a $5 \%$; ns: não-significativo.

efeito da calagem e adição da matéria seca do adubo verde (cobertura vegetal) e, em segundo lugar, porque a aplicação de lodo de esgoto eleva significantemente os teores de nutrientes no solo, comparados com o tratamento sem sua aplicação (Galdos et al., 2004).

Para os macrorganismos, não houve significância estatística nos contrastes do tratamento 1 e os demais (Quadro 9), significando que a macrofauna é semelhante entre a testemunha e os tratamentos de recuperação do solo. Os macrorganismos encontrados foram: besouro (ordem Coleoptera), centopéia (classe Chilopoda), aranha (ordem Araneae), minhoca (ordem Haplotaxida), cupim (ordem Isoptera), formiga (ordem Hymenoptera), tesourinha (ordem Dermaptera), barata (ordem Blattodea), além de pupas e larvas. No desdobramento da análise dos contrastes da testemunha com os tratamentos de recuperação, podese observar que o contraste dos tratamentos 1 x 6 foi o único que apresentou alteração significativa. Neste caso, a diferença se deveu à presença de larvas no tratamento $\mathrm{AF}+\mathrm{B}+\mathrm{LE}$. Entre o solo do Cerrado e os demais tratamentos as diferenças ocorreram devido à presença de indivíduos no solo de Cerrado (cupim, centopéia, barata e minhoca), não encontrados na área degradada e em recuperação. Já no desdobramento dos contrastes entre o Cerrado e demais tratamentos, nestes foi verificada a presença de larva (tratamento $\mathrm{AF}+\mathrm{B}+\mathrm{LE}$ ), formiga (tratamentos $\mathrm{AF}, \mathrm{AF}+\mathrm{CE}$ e $\mathrm{AF}+\mathrm{RS})$, besouro (AF + B + LE) e cupim e centopéia (Cerrado). Entre os tratamentos de recuperação do solo, de forma geral eles foram semelhantes, porém destaca-se o tratamento $\mathrm{AF}+\mathrm{B}+\mathrm{LE}$, pois este diferiu do tratamento AF com relação ao número de larva e besouro e, também, do tratamento $\mathrm{AF}+\mathrm{CE}$ quanto ao número de besouros, o que significa que está sendo melhor na recuperação da macrofauna do solo. Isso pode ser explicado devido à presença de larva (de coleoptero), pois, segundo Uzeda (1999), a presença de Brachiaria decumbens favorece a diminuição da temperatura do solo, manutenção da umidade e é fonte de alimento para a macrofauna do solo. Segundo Correia \& Andrade (1999), quanto mais diversa for a 
cobertura vegetal, maior será a diversidade das comunidades de fauna; conseqüentemente, surgirá uma colonização de várias espécies de fauna do solo com estratégias diferentes de sobrevivência (Moço et al., 2005).

\section{CONCLUSÕES}

1. A combinação da mobilização do solo e mobilização mais adição de matéria orgânica (adubos - cobertura - verdes e lodo de esgoto), para o solo estudado, modifica positivamente as propriedades físicas e químicas do horizonte $\mathrm{A}$.

2. A densidade do solo foi a propriedade física mais sensível para detectar alterações na recuperação do solo estudado.

3. As propriedades químicas do solo estão sendo recuperadas e, para isso, a adubação orgânica com lodo de esgoto, em curto prazo, foi mais eficaz.

4. Os tratamentos proporcionaram resultados no que se refere à população de macrorganismos do solo, sendo o tratamento com Astronium fraxinifolium + Brachiaria decumbens + lodo de esgoto o mais promissor. A presença de besouro (fases jovem e adulta) foram os indicadores de diversidade da macrofauna do solo em recuperação.

\section{LITERATURA CITADA}

AGUIAR, A.V.; SILVA, A.M.; MORAES, M.L.T.; FREITAS, M.L.M. \& BORTOLOZO, F.R. Implantação de espécies nativas para recuperação de áreas degradadas em região de Cerrado. In: SIMPÓSIO NACIONAL DE RECUPERAÇÃO DE ÁREAS DEGRADADAS, 4., 2000, Blumenau. Anais. Blumenau, Sociedade Brasileira de Recuperação de Áreas Degradadas, Fundação Universidade Regional de Blumenau, 2000. CD-ROM.

ALVES, M.C. Recuperação do subsolo de um Latossolo Vermelho usado para terrapleno e fundação da usina hidrelétrica de Ilha Solteira. Ilha Solteira, Universidade Estadual Paulista, 2001. 83p. (Tese de Livre Docência)

ALVES, M.C. \& SUZUKI, L.E.A.S. Influência de diferentes sistemas de manejo do solo na recuperação de suas propriedades físicas. Acta Sci. Agron., 26:27-34, 2004.

ANDREOLI, C.V.; PEGORINI, E.S. \& FERNANDES, F. Disposição do lodo de esgoto no solo. In: ANDREOLI, C.V.; Von SPERLING, M. \& FERNANDES, F., coords. Lodo de esgotos: Tratamento e disposição final. Belo Horizonte, DESA/UFMG, SANEPAR, 2001. v.6. p.319-395.

ARAUJO, M.A.; TORMENA, C.A.; SILVA, A.P.A. \& MENDONÇA, E. Propriedades físicas de um Latossolo Vermelho distrófico cultivado e sob mata nativa. R. Bras. Ci. Solo, 28:337-345, 2004.
BITAR, O.Y. Avaliação da recuperação de áreas degradadas por mineração na região metropolitana de São Paulo. São Paulo, 1997. 185p.

CAMARGO, F.A.O.; GIANELLO, C.; TEDESCO, M.J. \& VIDOR, C. Nitrogênio orgânico do solo. In: SANTOS, G.A. \& CAMARGO, F.A.O., eds. Fundamentos da matéria orgânica do solo: Ecossistemas tropicais e subtropicais. Porto Alegre, Gênesis, 1999. p.117-137.

CAMARGO, O.A.; CASTRO, O.M.; VIEIRA, S.T. \& QUAGGIO, J. A alteração de atributos químicos do horizonte superficial de um Latossolo e um Podzólico com a calagem Sci. Agric., 54:1-8, 1997.

CAMILOTTI, F.; ANDRIOLI, I.; DIAS, F.L.F.; CASAGRANDE, A.A.; DA SILVA, A.R.; MUTTON, M.A. \& CENTURION, J.F. Efeito prolongado de sistemas de preparo do solo com e sem cultivo de soqueira de cana crua em algumas propriedades físicas do solo. Eng. Agric., 25:189-198, 2005.

CAMPOS, F.S. Propriedades físico-químicas de um solo em recuperação sob sistema agrosilvopastoril. Ilha Solteira, Universidade Estadual Paulista, 2004. 61p. (Trabalho de Graduação)

CENTRAIS ELÉTRICAS DO ESTADO DE SÃO PAULO CESP. Diretoria de Meio Ambiente e Recomposição Vegetal. São Paulo, 1998. 11p.

CORREIA, M.E.F. \& ANDRADE, A.G. Formação de serapilheira e ciclagem de nutrientes. In: SANTOS, G.A. \& CAMARGO, F.A.O., eds. Fundamentos da matéria orgânica do solo: Ecossistemas tropicais e subtropicais. Porto Alegre, Gênesis, 1999. p.197-226.

DEMATTÊ, J.L.I. Levantamento detalhado dos solos do Campus Experimental de Ilha Solteira. Piracicaba, 1980. 131p. Não Publicado.

DORAN, J.W. Soil quality and sustainability. In: CONGRESSO BRASILEIRO DE CIÊNCIA DO SOLO, 26., Rio de Janeiro, 1997. Anais. Rio de Janeiro, Sociedade Brasileira de Ciência do Solo, 1997. p.20-26.

EMPRESA BRASILEIRA DE PESQUISA AGROPECUÁRIA EMBRAPA. Centro Nacional de Pesquisa de Solos. Manual de métodos de análise de solo. 2.ed. Rio de Janeiro, 1997. $212 p$.

EMPRESA BRASILEIRA DE PESQUISA AGROPECUÁRIA EMBRAPA. Centro Nacional de Pesquisa de Solos. Sistema brasileiro de classificação de solo. Brasília, 1999. $412 \mathrm{p}$.

FRANCHINI, J.C.; GONZALEZ-VILA, F.J.; CABRERA, F.; MIYAZAWA, M. \& PAVAN, M.A. Rapid transformations of plant water-soluble organic compounds in relation to cation mobilization in an acid Oxisol. Plant Soil, 231:55-63, 2001.

GALDOS, M.V.; DE MARIA, I.C. \& CAMARGO, O.A. Atributos químicos e produção de milho em um Latossolo Vermelho eutroférrico tratado com lodo de esgoto. R. Bras. Ci. Solo, 28:569-577, 2004.

JORGE, J.A.; CAMARGO, O.A. \& VALADARES, J.M.A.S. Condições físicas de um Latossolo Vermelho-Escuro quatro anos após aplicação de lodo de esgoto e calcário. R. Bras. Ci. Solo, 15:237-240, 1991. 
LOPES, J.A.V. \& QUEIROZ, S.M.P. Rodovias e meio ambiente no Brasil: Uma resenha crítica. In: RECUPERAÇÃO DE ÁREAS DEGRADADAS, SIMPÓSIO SUL-AMERICANO, 1., e SIMPÓSIO NACIONAL, 2,. 1994, Curitiba. Anais. Curitiba, Fundação de Pesquisas Florestais do Paraná, 1994. p.75-90.

MELO, V.P.; BEUTLER, A.N.; SOUZA, Z.M.; CENTURION, J.F. \& MELO, W.J. Atributos físicos de Latossolos adubados durante cinco anos com biossólido. Pesq. Agropec. Bras., 39:67-72, 2004.

MELO, W.J.; MARQUES, M.O.; SANTIAGO, G.; CHELLI, R.A. \& LEITE, S.A.S. Efeito de doses crescentes de lodo de esgoto sobre frações da matéria orgânica e CTC de um Latossolo cultivado com cana-de-açúcar. R. Bras. Ci. Solo, 18:449-455, 1994.

MERLIM, A. Macrofauna edáfica em ecossistemas preservados e degradados de araucária no Parque Estadual de Campos de Jordão, SP. Piracicaba, Escola Superior de Agricultura Luiz de Queiroz, 2005. 89p. (Tese de Mestrado)

MIRANDA, L.N.; DE MIRANDA, J.C.C.; REIN, T.A. \& GOMES, A.C. Utilização de calcário em plantio direto e convencional de soja e milho em Latossolo Vermelho. Pesq. Agropec. Bras., 40:563-572, 2005.

MOÇO, M.K.S.; GAMA-RODRIGUES, E.F.; GAMARODRIGUES, A.C. \& CORREIA, M.E.F. Caracterização da fauna edáfica em diferentes coberturas vegetais na região norte fluminense. R. Bras. Ci. Solo, 29:555-564, 2005.

NASCIMENTO, J.T.; SILVA, I.F.; SANTIAGO, R.D. \& SILVA NETO, L.F. Efeito de leguminosas nas características químicas e matéria orgânica de um solo degradado. R. Bras. Eng. Agric. Amb., 7:457-462, 2003.

NEVES, L.G.; TIENNE, L. \& VALCARCEL, R. Regeneração induzida em áreas de empréstimo na Ilha da Madeira, RJ. In: JORNADA DE INICIAÇÃO CIENTÍFICA DA UFRRJ, 11., Seropédica, 2001. Resumos. Seropédica, Universidade Federal Rural do Rio de Janeiro, 2001. p.103-106.

PAGLIAI, M.; GUIDI, G.; LA MARCA, M.; GIACHETTI, M. \& LUCAMANTE, G. Effects of sewage sludges and composts on soil porosity and aggregation. J. Environ. Qual., 10:556561, 1981.

PAULINO, V.T.; BEISMAN, D.A. \& FERRARI Jr., E. Fontes de nitrogênio na recuperação de pastagens de Brachiaria decumbens durante o período da seca. Past. Trop., 17:2024, 1995 .

RAIJ, B.van \& QUAGGIO, J.A. Métodos de análises de solo para fins de fertilidade. Campinas, Instituto Agronômico, 1983. 31p. (Boletim Técnico, 81)

RAIJ, B.van.; CANTARELlA, H.; QUAGGIO, J.A. \& FURLANI, A.M.C., eds. Adubação orgânica. In: Recomendações de adubação e calagem para o Estado de São Paulo. 2.ed. Campinas, Instituto Agronômico, 1997. p.30-35. (Boletim Técnico, 100)
RAIJ, B.van; De ANDRADE, J.C.; CANTARELLA, H. \& QUAGGIO, J.A., eds. Análise química para avaliação da fertilidade de solos tropicais. Campinas, Instituto Agronômico, 2001. 284p.

REICHERT, J.M.; REINERT, D.J. \& BRAIDA, J.A. Qualidade do solo e sustentabilidade de sistemas agrícolas. R. Ci. Amb., 27:29-48, 2003.

SAS Institute. SAS/STAT User's guide: Version 6.4.ed. Cary, 1990. v.2.

SILVA, F.C.; BOARETTO, A.E.; BERTON, R.S.; ZOTELLI, H.B.; PEIXE, C.A. \& MENDONÇA, E. Cana-de-açúcar cultivada em solo adubado com lodo de esgoto: Nutrientes, metais pesados e produtividade. Pesq .Agropec. Bras., 33:1-8, 1998.

SILVA, F.C.; BOARETTO, A.E.; BERTON, R.S.; ZOTELLI, H.B.; PEXE, C.A. \& BERNARDES, E.M. Efeito de lodo de esgoto na fertilidade de um Argissolo VermelhoAmarelo cultivado com cana-de-açúcar. Pesq. Agropec. Bras., 36:831-840, 2001.

SILVA, S.M.C.P.; FERNANDES, F.; SOCCOL, V.; WISNIEWSKI, C.; NETO, J.A.M.; PEREIRA, A.M.; RADOMSKI, M.I. \& SESSEGOLO, G.C. Uso do lodo de esgoto da ETE-Belém na recuperação de áreas degradadas por mineração de calcário. Sanare, 5:76-85, 1996.

SIMONETE, M.A.; KIEHL, J.C.; ANDRADE, C.A. \& TEIXEIRA, C.F.A. Efeito do lodo de esgoto em um Argissolo e no crescimento e nutrição de milho. Pesq. Agropec. Bras., 38:1187-1195, 2003.

STENBERG, B. Monitoring soil quality of arable land: Microbiological indicators. Acta Agric. Scandinavica, B, 49:1-24, 1999

TAKEDA, H. Templates for the organization of collembolan communities. In: EDWARDS, C.A.; ABE, T. \& STRIGANOVA, B.R., eds. Structure and function of soil communities. Kyoto, Kyoto University, 1995. p.5-20.

TAMANINI, C.R. Recuperação de áreas degradadas com a utilização de biossólido e gramínea forrageira. Curitiba, Universidade Federal do Paraná, 2004.181p. (Tese de Mestrado)

UZÊDA, M.C. Parâmetros de solo como indicadores de sustentabilidade em um agroecossistema com morango (Fragaria x anassa Duch), em São Roque. Campinas, 1999. $105 \mathrm{p}$.

VAZ, L.M.S. \& GONÇALVES, J.L.M. Uso de biossólidos em povoamento de eucalipto; efeito em atributos químicos do solo, no crescimento e na absorção de nutrientes. R. Bras. Ci. Solo, 26:747-758, 2002.

VIDAL, V.E. \& ALVES, M.C. Estudio de la macrofauna de un solo tropical. In: BIENAL, 15., La Coruña, 2003. Anais. La Coruña, Sociedad Española de un Suelo Tropical, 2003. p.44. 